\title{
Nasofarinks biyopsi uygulanan hastaların klinikopatolojik verilerinin analizi: tek merkezli retrospektif çalışma
}

\section{Analysis of the clinicopathological data of patients undergoing nasopharyngeal biopsy: a single centered retrospective study}

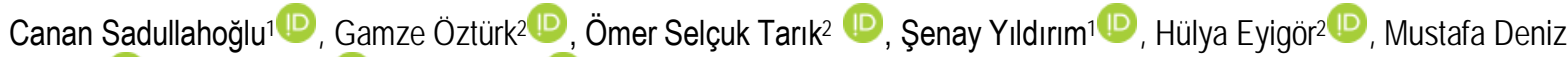 \\ Yılmaz² $^{\mathbb{D}}$, Üstün Osma² ${ }^{\mathbb{D}}$, Cem Sezer ${ }^{1} \mathbb{D}$
}

1 Sağlık Bakanlığı Üniversitesi Antalya Eğitim ve Araştırma Hastanesi, Patoloji Kliniği, Antalya, Türkiye

2 Sağlık Bakanlığı Üniversitesi Antalya Eğitim ve Araştırma Hastanesi, Kulak Burun Boğaz Kliniği, Antalya, Türkiye

Öz.

Amaç: Bu çalışmanın amacı, retrospektif olarak nazofaringeal patoloji nedeniyle biyopsi yapılan hastaların klinikopatolojik özelliklerini analiz etmektir.

Materyal ve Metot: Ocak 2009-Temmuz 2018 tarihleri arasında nazofaringeal lezyonu tanımlamak amacıyla 535 hastaya biyopsi yapıldı. Klinik ve patolojik verileri retrospektif olarak

kayit edildi. İstatistiksel olarak analiz edildi.

Bulgular: Çalışmaya dahil edilen 535 olgunun 311 'ü erkek ve 224'ü kadın İdi. Yaş ortalaması $37.7 \pm 17$ 'di. En sık izlenen benign lezyon reaktif lenfoid hiperplazi ve en sık malign lezyon nazofarinks karsinomu idi. Yaş arttıkça malignite saptanma oranının arttığı tespit edildi.

Sonuç: Illeri yaşlarda nazofarinkste tanımlanan lezyonların malign olma olasılığı yüksektir. Bu yüzden, semptomatik olgularda doğru tanı için öncelikle klinikopatolojik korelasyon gereklidir.

Anahtar sözcükler: Nazofarinks biyopsisi, Nazofarinks karsinomu, Nazofaringeal lezyonlar

\section{Abstract}

Background: The aim of this study was to retrospectively analyze the clinicopathological features of patients who underwent biopsy because of nasopharyngeal pathology in our hospital.

Methods: Between January 2009- July 2018, 535 patients underwent biopsy to identify the nasopharyngeal lesion. Clinical and pathological data recorded retrospectively and evaluated statistically.

Results: 535 patients were included in the study, 311 were male and 224 were female. The mean age was $37.7 \pm 17$. The most common benign lesion was reactive lymphoid hyperplasia and the most common malignant lesion was nasopharyngeal carcinoma. It was determined that the rate of detection of malignancy increased with age.

Conclusion: Lesions identified in nasopharynx at advanced ages are likely to be malignant. Therefore, for correct diagnosis in symptomatic cases, firstly clinicopathological correlation is necessary.

Keywords: Nasopharyngeal biopsy, Nasopharyngeal carcinoma, Nasopharyngeal lesions
Sorumlu Yazar I

Corresponding Author

Dr. Canan SADULLAHOĞLU

Sağlık Bakanlığı Üniversitesi

Antalya Eğitim ve Araştırma Hastanesi,

Patoloji Kliniği,

Antalya, Türkiye

Tel: +90 5366757325

E-mail: canan-rana@hotmail.com

Geliş tarihi / Received: 16.11.2018

Kabul tarihi / Accepted: 10.05.2019

DOI: 10.35440/hutfd.482816 


\section{Giriş}

Nasofarinks, respiratuar pasajın üst kısmını oluşturan nazal boşluk arkasında yer alan ve yumuşak damağa kadar uzanım gösteren farinksin bir parçasıdır $(1,2)$. Histolojik olarak yüzey epiteli, bağ ve zengin lenfoid doku komponenti içeriyor olması nedeniyle çeşitli non-neoplastik ve neoplastik hastalıklar izlenmektedir (1). Hastalar, burun tıkanıklı̆ı ve kanaması, seröz otit, boyunda kitle gibi hem nonneoplastik hem de neoplastik hastalıklarda izlenebilen spesifik olmayan semptomlar ile başvururlar (3). Semptomatik olgularda kulak burun boğaz muayenesinde endoskopik nazofaringoskopi özellikle erken evrede nazofarinks karsinomu teşhis etmede altın standartır $(3,4)$.

Nazofarinks tümörleri, 2017 Dünya Sağlık Örgütünün sınıflamasına göre en sık izlenen malign epitelyal tümörler; keratinize skuamöz hücreli karsinom, non-keratinize skuamöz hücreli karsinom ve bazal hücreli karsinom olarak 3'e ayrlır. Non-keratinize skuamöz hücreli karsinom histomorfolojik olarak differansiye ve undifferansiye olarak ikiye ayrılmasına karşın bu ayrımın klinik ve prognostik değeri yoktur (5).

Amacımız, 9 yıllık bir süreçte şüpheli nazofaringeal lezyonları tanımlamak için alınan biyopsi sonuçlarını klinik ve patolojik verilerle karşılaştırmak.

\section{Materyal ve Metot}

Ocak 2009-Temmuz 2018 tarihleri arasında Kulak Burun Boğaz Hastalıkları Kliniği'ne başvuran ve klinik değerlendirme sonucu nazofarinks biyopsisi alınan 535 hastanın kayıtları retrospektif olarak incelendi. Çalışma protokolü hastanemiz etik kurulu tarafından onaylandı (Protokol no:2018-212).

Kulak Burun Boğaz polikliğine burun tıkanıklı̆ı ve kanama, boyunda şişlik, kulak çınlaması ve benzeri yakınmalar ile başvuran hastalara lokal veya genel anestezi altında transnazal endoskopi yardımıyla şüpheli lezyondan ve alanlardan nazofarinks biyopsisi alındı. Elde edilen biyopsi materyalleri özel koruyucu solüsyon içeren kaplar içerisinde histopatolojik inceleme amacıyla patoloji laboratuvarımıza gönderildi. Çalışmaya dahil edilen hastaların yaşı, cinsiyeti, başvuru semptomu ve patolojik tanıları retrospektif olarak kayıt edildi. Patolojik tanıları benign ( non-neoplastik ve benign neoplastik) ve malign olarak ayrıldı. Malign ve benign neoplastik tanıları Dünya Sağlık Örgütü 2017 göre sınıflandırıldı (5).

Elektronik ortamda SPSS 17.0 versiyonu ( PSS, Inc., Chicago, IL, ABD) kullanılarak tanımlayıcı istatistikler; sayısal değişkenler için ortalama, standart sapma, minimum, maksimum, kategorik değişkenler sayı ve yüzde olarak verilmiştir. Kategorik değişkenlerin grup karşılaştırması için kikare testi kullanıldı ve 0.05 'ten küçük bir $p$ değeri istatistiksel olarak anlamlı kabul edildi.

\section{Bulgular}

Çalışmaya dahil edilen 535 olgunun 311'ü erkek 224'ü kadın idi. Yaş aralığı 3-89 arasında olup ortalama yaşı $37.7 \pm 17$ idi.

Benign lezyonlarda en sık başvuru semptomu burun tıkanıklığı \%53.7 (249/464) iken malign lezyonlarda ise boyunda şişlik \% 43.6 (31/71) idi (Tablo1).

Tablo 1. Benign ve malign lezyonlarda izlenen semptomlar

\begin{tabular}{lll}
\hline Semptomlar & Benign $\mathbf{n}(\%)$ & Malign $\mathbf{n}(\%)$ \\
\hline Burun Tıkanıkı̆̆ı & $249(\% 53.7)$ & $19(\% 28.8)$ \\
Burun Kanaması & $9(\% 1.9)$ & 0 \\
Isşitme Kaybı & $127(\% 27.4)$ & $20(\% 28.1)$ \\
Kulak Çınlaması & $15(\% 3.2)$ & 0 \\
Boyunda Şişlik & $40(\% 8.6)$ & $31(43.6)$ \\
Diğer & $24(\% 5.2)$ & $1(\% 1.4)$ \\
\hline Toplam $\mathbf{n}$ & $\mathbf{4 6 4}$ & $\mathbf{7 1}$ \\
\hline
\end{tabular}

Olguların \%86.7'inde (464/535) benign lezyon (330 reaktif hiperplazi, 125 kronik, 5 Tornwaldt kisti, 3 granülomatöz inflamasyon, 1 anjiofibrom) saptanırken \%13.3'ünde ( 71/535) malign lezyon izlendi. Malign lezyonların \%77.4'ü (55/71) karsinomlar, \%21.1'u (15/71) hematolenfoid tümörler ve \%1.5'ü (1/71) notokordal tümörden oluşmaktaydı (Tablo 1). Karsinomların ise \% 87.2'i (48/55) non-keratinize skuamöz hücreli karsinom, andiferansiye tip'dir. En sık izlenen ikinci malign tümör olan hematolenfoid tümörlerin 1'i Hodgkin lenfoma,11'i non-hodgkin lenfoma (9 diffüz büyük B hücreli lenfoma, 2 Manthle zon lenfoma), 3'ü T hücreli lenfoma idi (Tablo 2). Malign lezyonların \%46.4'ü (33/71) 41-60 yaş ve \%36.4'ü (26/71) 60 yaş üstünde izlendi. Malign lezyonların \% 73.2'i erkek cinsiyette saptandı (Tablo 2). Çocuk, genç ve genç erişkin yaş aralı̆ı̆nda alınan biyopsilerin malign olma olasııı̆ı \%3.5 ve \%3.9 iken yaş artıkça özelliklede 60 yaş üzerinde alınan biyopsilerde malign lezyon saptanma oranı \%44'e çıkmaktadır (Tablo 3).

\section{Tartışma}

Klinik veriler ve radyolojik incelemeler nazofarinks lezyonlarının benign yada malign olup olmadığını değerlendirmede ilk basamak olmalarına rağmen kesin tanı histopatolojik incelemedir. Nazofarinks karsinomuyla karşılaştıııldığında bu bölgenin tüm lezyonlarının klinik ve histopatolojik verilerini sunan sınırlı sayıda çalışma mevcuttur $(4,6,7)$.

Berkiten ve arkadaşlarının 8 yıllık deneyimlerini sundukları çalışmada 1647 hastanın ortalama yaşı bizim çalışmamıza benzer şekilde 36 olarak rapor edildi (6). Nazofarinks karsinomunun görülme yaşı coğrafi farklılıklara bağlı olarak değişmesine rağmen en sık 40-50 yaşlarında ve erkeklerde izlenir (1). Bizim çalışmamızda da en sık 40-60 yaş aralığında ve erkeklerde saptandı.

Nazofarinksin benign ve malign lezyonları spesifik semptom vermesede yapılan çalışmalarda benign lezyonlarda 
en sık burun tıkanıkığı saptanırken malign lezyonlarda ise boyunda şişlik ve işitme kaybı izlenmiştir $(6,8,9)$. Bizim çaıışmamızda, benign ve malign lezyonlarda izlenen semptomlar literatürle uyumludur.

Lenfoid doku hipertrofisi yaşamın illk 4 yılında izlenir ve genellikle 6 ile 16 yaş aralı̆ı̆ında genellikle involüsyona uğrar. Erişkinlerde izlenen lenfoid doku hiperplazisinden ise toz, sigara ve allerjik hastalıklar gibi dış etkenler yanı sıra viral ve bakterial enfeksiyonlar suçlanmaktadır. Hiperplazinin nedeni tam olarak bilinmesede klinik olarak nazofarinks maligniteleri ile karıştırılabilir (10). Geniş olgu serisine sahip Berkiten ve arkadaşlarının yaptığı çalışmada, nasofarinks biyopsilerinin \%97.4'ü benign lezyon ve bu lezyonların \%92.72 reaktif doku hiperplazisinden oluşmaktaydı (6). Bizim çalışmamızda da olguların $\% 86.5$ benign ve bu olguların $\% 71.1$ reaktif lenfoid hiperplazi ve $\% 26.9$ 'u kronik inflamasyondu.

Tablo 2. Tüm olguların yaş aralığı ve cinsiyete göre histopatolojik tanıları.

\begin{tabular}{|c|c|c|c|c|c|c|c|c|}
\hline \multirow{2}{*}{\multicolumn{3}{|c|}{ Nazofarinks Benign Lezyonları $(n=464)$}} & \multicolumn{4}{|c|}{ Yaş aralığı } & \multicolumn{2}{|l|}{ Cins } \\
\hline & & & $0-18$ & $19-40$ & $41-60$ & $>60$ & Erkek & Kadın \\
\hline \multicolumn{3}{|c|}{ Kronik eflamasyon $(n=125)$} & 15 & 58 & 39 & 13 & 80 & 45 \\
\hline \multicolumn{3}{|c|}{ Reaktif Lenfoid Hiperplazisi (n=330) } & 67 & 163 & 82 & 18 & 174 & 156 \\
\hline \multicolumn{3}{|c|}{ Granülomatöz ( $n=3)$} & 0 & 0 & 2 & 1 & 1 & 2 \\
\hline \multicolumn{3}{|c|}{ Tornwaldt Kisti (n=5) } & 0 & 1 & 4 & 0 & 3 & 2 \\
\hline \multicolumn{3}{|c|}{ Anjiofibrom(n=1) } & 0 & 0 & 0 & 1 & 1 & 0 \\
\hline \multicolumn{3}{|c|}{ Benign lezyon $\mathrm{n}(\%)$} & $\begin{array}{l}82 \\
(\% 17.6)\end{array}$ & $\begin{array}{l}222 \\
(\% 47.8)\end{array}$ & $\begin{array}{l}127 \\
(\% 27.3)\end{array}$ & $\begin{array}{l}33 \\
(\% 7.3)\end{array}$ & $\begin{array}{l}259 \\
(\% 55.8)\end{array}$ & $\begin{array}{l}205 \\
(\% 44.2)\end{array}$ \\
\hline \multicolumn{9}{|c|}{ Nazofarinks Malign Lezyonları (n=71) } \\
\hline \multirow{3}{*}{$\begin{array}{l}\text { Karsinomlar } \\
(n=55)\end{array}$} & \multicolumn{2}{|c|}{$\mathrm{K}-\mathrm{SHK}(\mathrm{n}=7)$} & 0 & 0 & 3 & 4 & 7 & 0 \\
\hline & NK-SHK & D & 0 & 0 & 4 & 0 & 2 & 2 \\
\hline & $(n=48)$ & $A D$ & 1 & 8 & 22 & 13 & 33 & 11 \\
\hline Hematolenfoid & $\mathrm{HL}(\mathrm{n}=1)$ & & 0 & 1 & 0 & 0 & 1 & 0 \\
\hline \multirow[t]{2}{*}{ Tümörler ( $n=15)$} & $\mathrm{NHL}(\mathrm{n}=14)$ & B Hücreli & 2 & 0 & 1 & 8 & 6 & 5 \\
\hline & & T Hücreli & 0 & 0 & 2 & 1 & 3 & 0 \\
\hline \multicolumn{3}{|l|}{$\begin{array}{l}\text { Notokordal Tü- } \\
\text { mörler(n=1) }\end{array}$} & 0 & 0 & 1 & 0 & 0 & 1 \\
\hline \multicolumn{3}{|c|}{ Malign lezyon n (\%) } & $\begin{array}{l}3 \\
(\% 4.6)\end{array}$ & $\begin{array}{l}9 \\
(\% 12.6)\end{array}$ & $\begin{array}{l}33 \\
(\% 46.4)\end{array}$ & $\begin{array}{l}26 \\
(\% 36.4)\end{array}$ & $\begin{array}{l}52 \\
(\% 73.2)\end{array}$ & $\begin{array}{l}19 \\
(\% 26.8)\end{array}$ \\
\hline
\end{tabular}

K-SHK: Keratinize skuamöz hücreli karsinom, NK-SHK:Non-keratinize skuamöz hücreli karsinom, D:Differansiye, AD:Andifferansiye

Tablo 3. Yaş aralığına göre izlenen benign ve malign lezyonların oranı.

\begin{tabular}{lllll}
\hline Yaş aralığı & Benign & \multicolumn{2}{l}{ Malign } & Toplam \\
\cline { 2 - 3 } & Non-neoplastik & $\begin{array}{l}\text { Benign } \\
\text { Neoplazm }\end{array}$ & \\
\hline $0-18$ & $82(\% 96.5)$ & 0 & $3(\% 3.5)$ & 85 \\
$19-40$ & $222(\% 96.1)$ & 0 & $9(\% 3.9)$ & 231 \\
$41-60$ & $127(\% 78.9)$ & 0 & $33(\% 20.1)$ & 160 \\
$60>$ & $32(\% 53.3)$ & $1(\% 1.7)$ & $26(\% 44)$ & 59 \\
Toplam & 464 & & 71 & 535 \\
\hline
\end{tabular}


Ayrıca bu bölgede yine malign lezyonlarla karışan kistik oluşumlar izlenebilir. Tornwardlt kisti, nazofarinks arka duvarında faringeal bursanın kalıc dilatasyonu sonucu oluşur. Tornwaldt kistleri tipik olarak $1 \mathrm{~cm}$ 'den küçük ve asemptomatiktir. Fakat orifisinin tıkanması, kistik bir dilatasyona, iltihap daha sonrada abse oluşumuna neden olabilir. Bu durum burun tıkanıklığı, baş ve kulak ağıısı yanı sıra boyun kaslarında kasılmaya neden olur (2). Bercin ve arkadaşlarının yaptığı ve 938 benign lezyon içeren çalışmada $\% 6$ ve 562 hasta içeren diğer çalışmada ise $\% 0.4$ 'tür $(6,11)$. Literatürle uyumlu olarak çalışmamızda izlenen tornwaldt kisti benign lezyonların yaklaşık \%1'ini (5/464) oluşturmaktaydı.

Nazofaringeal karsinomlar, tüm baş boyun tümörlerinin \%2'inden azını oluşturmasına rağmen agresif tümörlerdir (7). Erken dönemde tanı konduğu takdirde küratif olabilen bu tümörlerin yarısından fazlası ileri evrede tanı almaktadır (12). Yapılan önceki çalışmalarda nazofarinkste izlenen en sık malign tümörler sırasıyla nazofarinks ve hematolenfoid malignite olduğu bildirilmiş̧ir $(4,6,11,13,14)$. Literatürle uyumlu olarak malign olgularımızın \%77.4'ü nazofaringeal karsinom ve \%21.1'i ise hematolenfoid maligniteden oluşmaktaydı. Ayrıca malign lezyonların \%46.4'ü (33/71) 41-60 yaş aralığı ve \%36.4'ü (26/71) 60 yaş üstünde izlendi. Çocuk, genç ve genç erişkin yaş aralığında alınan biyopsilerin malign olma oranı $\% 3.5$ ve \%3.9 iken yaş artıkça özelliklede 60 yaş üzerinde alınan biyopsilerde malign lezyon saptanma oranı \% 45 'e çıkmaktadır. Berkiten ve arkadaşlarının yaptıkları çalışmada da yaşla birlikte malignite riskinin arttığı bildirilmiştir (6).

Sonuç olarak, nazofarinksin malign lezyonları, bu bölgenin benign lezyonlarına göre daha az sıklıkla izlenmesine rağmen spesifik semptom içermemesi ve erken tanının tedavi açısından önemli olması nedeniyle şüpheli olgularda kesin tanıya ulaşmada öncelikle histopatolojik incelemenin gerekli olduğunu düşünmekteyiz.

\section{Kaynaklar}

1. Özcan KM. Nazofarinks tümörleri. In: Midilli R, ed. Kulak Burun Boğaz Baş Boyun Cerrahisi, 1st. Ankara: Matsa Basımevi, 2016:301313.

2. Regauer S. Nasopharynx and Waldeyer's ring. In: Cardesa A, Slootweg PJ, eds. Pathology of the Head And Neck, 1st. Germany: Springer Berlin Heidelberg, 2006:172-191.

3. Arslan N, Tuzuner A, Koycu A, Dursu S, Hucumenoglu S. The role nasopharyngeal examination and biopsy in the diagnosis of malignant diseases. Braz J Otorhinolaryngol 2018; doi: 10.1016/j.bjorl.2018.04.006

4. Binesh F, Shajari A, Abdollahi S and Behniafard N. Ten years of experience in clinicopathologic characterristics, treatment and outcome of patients with nasopharyngeal pathologies in Yazd, Iran. Electronic Physician 2016;10:3081-3087.

5. Chan JKC, Slootweg PJ. Tumours of the nasopharynx. In: El naggar AK, Chan JKC, Grandis JR, Takata T, Slootweg PJ, eds. WHO Classification of head and Neck Tumours. 4th. Lyon:IARC:63-70.

6. Berkiten G, Kumral TL, Yildirim G, Uyar Y, Atar Y, Salturk Z: Eight years of clinical findings and biopsy results of nasopharyngeal pathologies in 1647 adult patients: a retrospective study. B-ENT 2014;
10(4): 279-84.

7. Tutar B, Berkiten T, Kumral TL, Yıldırım G, Uyar Y. Nazofarenks patolojilerinde punch biyopsi sonuçları: Üç yıllık retrospektif analiz. Okmeydanı Tıp Dergisi 2014;30-33.

8. El-Taher M, Ali K and Aref Z. Histopathological patern of nasopharyngeal masses in adults. Otolaryngol 2017; 7:1-3.

9. Glynn F, Keogh IJ, Ali TA, Timon Cl, Donnelly M. Routine nasopharyngeal biopsy in adults presenting with isolated serous otitis media: Is it justified? J Laryngol Otol 2006; 120: 439-441.

10. Kamel RH, Ishak EA (1990) Enlarged adenoid and adenoidectomy in adults: Endoscopic approach and histopathological study. J Laryngol Otol 1990; 104: 965-967.

11. Bercin S, Yalciner G, Muderris T, Gul F, Deger HM, Kiris M. Pathological evaluation routine nasopharynx punch biopsy in the adult population: Is It really necessary? Clin Exp Otorhinolaryngol 2017; 10:283-287.

12. Loong HH, Ma BB, Chan AT. Update on the management and therapeutic monitoring of advanced nasopharyngeal cancer. Hematol Oncol Clin North Am 2008; 22:1267-1278.

13. Carvalho MA, Pinheiro SD, de Freitas MR, da Silva VC, Lima RC. Nasopharyngeal Biopsy Performed in an Otorhinolaryngology Service Clinical-histopathological Correlation. Intl Arch Otorhinolaryngol 2008; 12:71-76.

14. Bilici S, Yıldız M, Gökduman AR, Yiğit Ö. Clinical appearances in patients with nasopharyngeal malgnancy: retrospective analysis. KBB-forum 2017; 16:76-82. 